\title{
Prostate Cancer Decision-Making, Health Services, and the Family Physician Workforce
}

\author{
Marjorie A. Bowman, MD, MPA, and Anne Victoria Neale, PhD, MPH
}

Does untreated cancer equal death? Does having a registered nurse versus a licensed practical nurse versus a medical assistant affect diabetes quality outcomes? Do physicians caring for stressed patients experience vicarious traumatic stress? Oregon presents an operationalized definition of a patient-centered medical home for their state. Lots of important clinical topics in family medicine-adult attention deficit disorder office questionnaire; Bell palsy; cancer screening and treatment decisions; lubrication during Papanicolaou testing; changes in maternity care training by residencies; changing prescribing patterns for thiazide diuretics; and night sweats remain a mystery. ( $\mathrm{J}$ Am Board Fam Med 2012;25: 753-755.)

Untreated cancer equals death? This is the underlying fear and myth that drives many patients. However, there is the corresponding assumption than an unfound cancer is not a deadly cancer and a found cancer is a deadly cancer. With prostate cancer screening, we would argue, the main issue is not the prostate-specific antigen test itself, certainly an imperfect test, but what happens afterward. Having a lower level of prostate-specific antigen does not require immediate treatment. This is not a myth, but it is very difficult concept for patients and physicians. Once men know the cancer is actually present (as compared with the large number of men whom have prostate cancer but do not know it), they struggle to decide to watch and wait. For those who consider watchful waiting, significant others and physicians often pushed toward active treatment. Read some of the telling comments in $\mathrm{Xu}$ et al. ${ }^{1}$

Three articles in this issue are on colon cancer screening. Baldwin et $\mathrm{al}^{2}{ }^{2}$ in a study with an excellent methodology, observed physicians with high or low patient screening rates with simulated patients and compared the 2 groups of physicians. Their results provide dramatic help in how to get patients to carry through with screening, including consequence messaging and problem solving (see the article for more). Fagan et $\mathrm{al}^{3}$ note that patients who are obese

From the American Board of Family Medicine, Lexington, $\mathrm{KY}$.

Funding: none.

Conflict of interest: The authors are editors of the JABFM. do not understand they have an increased risk of colon cancer, yet those who perceived higher risk were more likely to follow through with screening, so we should provide this helpful information to the appropriate patients. Furthermore, Hudson et $\mathrm{al}^{4}$ found that women and smokers were less likely to report receiving recommendation for colorectal cancer screening (CRC) and also identified factors related to nonscreening for patients who did report having a recommendation. Interestingly, the patients in the Hudson et $\mathrm{al}^{4}$ study were far more likely to report having received recommendations for CRC (go New Jersey!) than those in the Fagan et al study ${ }^{3}$ that reported data from the National Health Interview Survey.

\section{Clinical Management}

Several of our reports provide additional data on clinical areas of controversy. Guler et $\mathrm{al}^{5}$ completed a large study (400 women) providing more information on the lubrication/no lubrication argument during Papanicolaou smear collection. The bottom line: lubrication was helpful for postmenopausal women but not for premenopausal women. Quality of the Papanicolaou smears was similar.

Antibiotic use in febrile children is another area of controversy in which guidelines and clinical practice often are not concordant. Berger et $\mathrm{al}^{6}$ looked at data on after-hours care for children in family medicine offices in The Netherlands where the percentage of febrile children receiving antibiotics has been increasing. The authors identified factors that appear to prompt antibiotic prescrip- 
tion that go over and beyond national guidelines, including one that may be surprising, that is, decreased reported urination. My (MAB) guess is that the physicians were concerned this could indicate a more seriously ill child. Appropriately, more antibiotics were prescribed when parents were particularly concerned or the physician thought the child looked particularly ill, because both of these factors are known to be related to the frequency of serious illness. Research in this area is somewhat complicated by fewer office visits by children with upper respiratory infection, ${ }^{7}$ perhaps because of publicity about avoiding antibiotics for upper respiratory infections.

We also have help with adult attention deficit disorder (ADD), a recognized disorder in adults, but without efficient diagnostic support. Curry et $\mathrm{al}^{8}$ evaluated a 6-question screening tool (ADHD SelfReport Scale-V1.1 [ASRS V1.1]), which was excellent at ruling out adult $\mathrm{ADD}$ and yet with very good sensitivity. A negative screening result indicated a very low likelihood of $\mathrm{ADD}$ and a positive screening suggested some additional probing to verify the diagnosis. The ASRS is a questionnaire that could be quite useful in the practice of family medicine.

Both diabetes and hypertension are increasing in the childbearing years and so has the use of teratogenic drugs for treating these medical problems. Force et $\mathrm{al}^{9}$ highlight a quality improvement project to help remind our healthcare providers to recognize and appropriately manage this issue. Hagen ${ }^{10}$ notes that the accumulating data on chlorthalidone as superior to hydrochlorothiazide for high blood pressure is associated with changes in the relative prescribing frequencies on the American Board of Family Medicine recertification examination. This suggests the examination could be a bellwether for understanding changes in drug-prescribing habits.

\section{Office Management for Quality, Health Services, and Patient-Centered Medical Home}

To improve diabetes care, perhaps we should pair registered nurses and physicians in our offices. In an Erickson et $\mathrm{al}^{11}$ study, the staffing ratios were controlled centrally, although there was variation in the type of staff pairings among medical assistants, licensed practical nurses, and registered nurses with physicians, nurse practitioners, or physician assistants. Overall performance on 5 diabetes measures and patient satisfaction was better with the registered nurse pairings, and with physician pairings, compared with nurse practitioners or physician assistants. The old saying is, " you get what you pay for," and that may be true here as well with the more expensive personnel associated with better diabetes outcome measures.

Reed and coauthors ${ }^{12}$ hypothesized that the trait of "grit," previously untested in physicians, might help us understand differences between urban and rural physicians and between primary care providers and specialists. It would stand to reason that perseverance despite adversity (a short version of the grit definition) should be related to satisfaction and could differ between these groups. The authors found very little differences, possibly because almost all physicians were satisfied with practice. Maybe more physicians should move to Idaho!

In an attempt to address difficulties with other definitions of the patient-centered medical home, the state of Oregon provides a very helpful operational definition of patient-centered medical home after a lengthy and involved process with multiple stakeholders. ${ }^{13}$ After years of decline, house calls to Medicare beneficiaries have increased in recent years ${ }^{14}$ probably related to increases in payment rates, yet there is certainly remaining unmet need.

\section{New Thoughts and Data}

Diabetes is widely thought to indicate a worse prognosis from Bell palsy, but Riga ${ }^{15}$ found otherwise. However, the severity of the Bell palsy was worse at presentation in those patients with diabetes.

Do physicians experience vicarious traumatic stress after observing various aspects of trauma experienced by their patients? Woolhouse ${ }^{16}$ used qualitative methods to explore the feelings of Canadian family physicians caring for inner-city women with substance use. The authors do very well at pulling out some of the compelling comments and thoughts of the family physicians in these practice settings and the mechanisms they use to deal with the vicarious trauma they experience.

\section{Education System Items with Effect on Family Physician Workforce}

We have 2 articles particularly related to the educational system with impact on the future of family medicine as a specialty. In a timely report, Meunier et $\mathrm{al}^{17}$ explore the perspectives of maternity care training directors in family medicine residencies on the proposed changes in maternity care requirements recommended by the Residency Review 
Committee. At the time of this writing, the outcome of this proposal at the level of the Accreditation Council for Graduate Medical Education is uncertain. However, there is no doubt that these changes can be very important to the future of obstetric deliveries in the practice of family medicine. Overall, a small percentage of programs will provide only the "20 delivery" model; and unopposed programs and those with family medicine obstetrical fellowships would be more likely to only have the " 80 delivery" model. More to come on this. On another note, Liaw et $\mathrm{a}^{18}$ verify that regional medical campuses are more likely to produce family physicians than centralized campuses.

\section{Clinical Reports}

Our brief reports provide helpful information and reminders: the sternoclavicular joint can be the site of septic arthritis ${ }^{19}$; the serious consequences of eosinophilic gastroenteritis ${ }^{20}$; and a reminder that vaccinations can cause serious difficulties along with helpful hints for relevant staff training. ${ }^{21}$

\section{JABFM in 2013}

In the upcoming year we have an exciting lineup of special theme issues, including 1 for Communities of Solution, which will publish during the first half of 2013. Also, we would like to take this opportunity to announce a call for papers for our 2013 annual practice-based research theme issue. Please note that submissions are due earlier than previous years with a January 14, 2013, deadline. All this and more in 2013!

\section{References}

1. Xu J, Neale AV, Dailey RK, Eggly S, Schwartz KL. Patient perspective on watchful waiting/active surveillance for localized prostate cancer. J Am Board Fam Med 2012;25:763-70.

2. O'Farrell CM, Green BB, Reid RJ, Bowen D, Baldwin LM. Physician-patient colorectal cancer screening discussions by physicians' screening rates. J Am Board Fam Med 2012;25:771-81.

3. Fagan HB, Sifri R, Wender R, Schumacher E, Reed JF. Weight status and perception of colorectal cancer risk. J Am Board Fam Med 2012;25:792-7.

4. Hudson SV, Ferrante JM, Ohman-Strickland P, et al. Physician recommendation and patient adherence for colorectal cancer screening. J Am Board Fam Med 2012;25:782-91.

5. Uygur D, Guler T, Yayci E, Atacag T, Comunoglu C, Kuzey GM. Association of speculum lubrication with pain and papanicolaou test accuracy. J Am Board Fam Med 2012;25:798-804.
6. Elshout G, Kool M, Van der Wouden JC, Moll HA, Koes BW, Berger MY. Antibiotic prescription in febrile children: a cohort study during out-of-hours primary care. J Am Board Fam Med 2012;25:810-8.

7. Miller GF, Hudson J. Children and antibiotics: analysis of reduced use, 1996-2001. Med Care 2006; 44(suppl):I36-44.

8. Hines JL, King TS, Curry WJ. The adult ADHD self-report scale for screening for adult attention deficit-hyperactivity disorder (ADHD). J Am Board Fam Med 2012;25:847-53.

9. Force RW, Keppel GA, Guirguis-Blake J, Gould DA, Vincent C, Chunchu K, et al. Contraceptive methods and informed consent among women receiving medications with potential for adverse fetal effects: a Washington. Wyoming, Alaska, Montana, Idaho (WWAMI) region study. J Am Board Fam Med 2012;25:661-8.

10. Hagen MD, Sumner W, Fu H. Diuretic of choice in hypertension ABFM self-assessment module simulations. J Am Board Fam Med 2012;25:805-9.

11. Erickson RA, Erickson RA, Targonski PV, Cox SB, Deming JR, Mold JW. Does the 'office nurse' level of training matter in the family medicine office? J Am Board Fam Med 2012;25:854-61.

12. Reed AJ, Schmitz D, Baker E, Nukui A, Epperly T. Association of 'grit' and satisfaction in rural and nonrural doctors. J Am Board Fam Med 2012;25:832-9.

13. Stenger RJ, Smith J, McMullan JB, et al. Defining the medical home: the Oregon experience. J Am Board Fam Med 2012;25:869-77.

14. Peterson L, Landers SH, Bazemore A. Trends in physician house calls to medicare beneficiaries. J Am Board Fam Med 2012;25:862-8.

15. Riga M, Kefalidis G, Danielides V. The role of diabetes mellitus in the clinical presentation and prognosis of Bell palsy. J Am Board Fam Med 2012;25:819-26.

16. Woolhouse S, Brown JB, Thind A. 'Building through the grief: vicarious trauma in a group of inner-city family physicians. J Am Board Fam Med 2012;25:840-6.

17. Meunier MR, Apgar BS, Ratcliffe SD, Mullan PB. Plans to accommodate proposed maternity care training requirements: a national survey of family medicine directors of obstetrics curricula. J Am Board Fam Med 2012;25:827-31.

18. Liaw W, Cheifetz C, Luangkhot S, Sheridan M, Bazemore A, Phillips R. Match rates into family medicine among regional medical campus graduates, 2007-2009. J Am Board Fam Med 2012;25:894-907.

19. Womack J. Septic arthritis of the sternoclavicular joint. J Am Board Fam Med 2012;25:908-12.

20. Ekunno N, Munsayac K, Pelletier A, Wilkins T. Eosinophilic gastroenteritis presenting with severe anemia and near syncope. J Am Board Fam Med 2012;25:913-8.

21. C, Hogan K. A "needling” problem: shoulder injury related to vaccine administration. J Am Board Fam Med 2012;25:919-22. 